\title{
LIBERAL ANTES DE SABERLO
}

\author{
Carlos Franz
}

\begin{abstract}
Mario Vargas Llosa era liberal antes de saberlo él mismo — se sostiene en estas páginas- - Al adoptar ese ideario, por consiguiente, fue consecuente con su modo más antiguo e íntimo de ver y expresar el mundo. Antes de que postulara una política de la libertad — se señala-, Vargas Llosa practicó una poética de la libertad. Y sus cinco novelas iniciales son más coherentes con el liberalismo, descubierto después, que con el marxismo revolucionario o el compromiso sartreano que profesaba cuando las escribía. A juicio de C. Franz, esa es la consecuencia que cabe pedirle a un artista: que sus ideas sigan a su mirada. No a la inversa.
\end{abstract}

Carlos Franz (1959). Licenciado en Derecho en la Universidad de Chile. Ha sido visiting fellow en las universidades de Cambridge y de Londres, donde residió varios años. Es autor de ensayos, cuentos y novelas. Entre estas últimas están Santiago cero (Alfaguara 2007; Premio Latinoamericano de Novela CICLA), El lugar donde estuvo el Paraíso (Alfaguara 2007), El desierto (Mondadori 2005; Premio de Novela La Nación de Buenos Aires), Almuerzo de vampiros (Alfaguara 2008). Algunos de sus libros han sido llevados al cine. Su libro de ensayos La muralla enterrada (Planeta 2011) obtuvo el Premio Municipal de Ensayo, en Santiago de Chile. Es colaborador habitual de diversas revistas y periódicos. Actualmente reside en Madrid. http://bib.cervantesvirtual. com/bib_autor/carlosfranz/ 
"Habia en mi manera de ser, en mi individualismo, en mi creciente vocación por escribir y en mi naturaleza díscola, una incapacidad visceral para ser ese militante revolucionario paciente, incansable, dócil..."

Mario Vargas Llosa, El pez en el agua

Leí La ciudad y los perros por primera vez a mis dieciséis años, en Chile. Recuerdo vívidamente la conmoción que me produjo. Como los protagonistas de esa novela yo estaba todavía en el colegio. Uno muy distinto a la escuela militar Leoncio Prado de Lima. El mío era un colegio civil y de elite; aunque no aseguraría qué tan civil era cualquier institución chilena en el año 1975, bajo Pinochet. Lo que me conmovió no fueron las similitudes casi escalofriantes entre esos dos institutos tan diferentes: en el mío también había un "Esclavo" y algún "Jaguar" y profesores cínicos y uno idealista. Ni fueron las semejanzas entre Chile y Perú, las divisiones sociales o el machismo reinante. Lo que me removió, hasta deprimirme y cerrar el libro con un nudo en la garganta, fue "presentir" que la derrota de esos cadetes peruanos podría ser la mía.

En el epílogo del libro tanto el Poeta como el Jaguar han sido derrotados. Fracasos parciales, porque han salido relativamente bien librados de la violencia de su colegio, son muy jóvenes y tienen "la vida por delante"; lo que por sí solo, a esa edad, simula una especie de victoria. Pero sus ilusiones acerca de ellos mismos han sido derrotadas.

Un nudo en la garganta al cerrar el libro. Aunque el final de la novela no era del todo amargo. También me ofrecía lo que entonces yo más ansiaba: la promesa de la vida adulta, con su peculiar libertad responsable. De aquellas derrotas parciales emanaba, a cambio, una fuerte sensación de autonomía. De libertad individual no como aventura sino como responsabilidad. Aceptación adulta de nuestra incapacidad de comprender plenamente un mundo inabarcable y caótico. Conciencia del límite hasta el cual es posible transformar la historia y cambiar la propia persona, sin hacer más daño que remedio. El Poeta y el Jaguar son libres para ser responsables de su correspondiente mediocridad (no evitemos la palabra).

Confirmé esa sensación con la lectura de las dos siguientes grandes novelas de Vargas Llosa. La Casa Verde y Conversación en La Catedral profundizaban aquella derrota - ahora en el sentido de "rumbo"- de sus protagonistas, llevados hacia una limitación asumida. 
Una mediocridad impuesta por fuerzas superiores e inextricables, pero también escogida por esos personajes. Relativización de sus ideales absolutos; moderación de sus ambiciones económicas y su radicalismo político; restricción de su propia independencia por respeto e incluso preferencia de la libertad ajena. Una autolimitación elegida como mal menor y, a menudo, hasta como acto de amor o nobleza. Para evitar dañar a quienes queremos, o no agregar más daño al mundo, cumplimos nuestros sueños parcialmente (si acaso).

Las dos siguientes novelas, las de la década de los setenta, Pantaleón y las visitadoras y La tía Julia y el escribidor, me sorprendieron como a mucha gente, supongo, por el registro humorístico y el desenfado políticamente incorrecto que encontré en ellas. Era como si esa libertad responsable y limitada de sus personajes anteriores hubiese sido el paradójico precio de una liberación del autor, que ahora satirizaba su seriedad anterior, incluso la que tuvo ante su oficio.

Cuando años después leí a los pensadores liberales (Berlin, Popper, Hayek) que Vargas Llosa estudió desde fines de los setenta, me sorprendió que las polémicas provocadas por su cambio de posición política no consideraran que esa visión liberal del mundo ya estaba presente - al trasluz, y por momentos hasta radiante- en sus cinco primeras novelas. Quienes intentaban separar las obras de Vargas Llosa de sus nuevas ideas parecían no haber leído las primeras ni comprendido las segundas. No aceptaban el coherente realismo de sus sueños. Me sigue sorprendiendo.

\section{Consecuente con su mirada}

Vargas Llosa ha relatado cómo, a fines de la década de los setenta y a comienzos de los ochenta, leyó a varios filósofos liberales. En ellos encontró una ideología nueva, en reemplazo de aquella que se había cuarteado y finalmente desmoronado, junto con su descubrimiento de la naturaleza totalitaria de la revolución cubana y de los socialismos reales en general. Ese desengaño histórico lo habría conducido a revisar sus ideas políticas y luego a reemplazarlas por otras, más coherentes con su nueva visión del mundo ${ }^{1}$.

${ }^{1}$ Esas búsquedas ideológicas tenían precedentes: a sus iniciales simpatías comunistas, en los cincuenta, siguió una breve pero significativa militancia demócrata cristiana. 
Una lectura clave fue la de Karl Popper. Como sabemos, La sociedad abierta y sus enemigos es una acerba - y hasta enconada - crítica a Platón, cuya utopía política, una república perfecta pero sin libertad (salvo para seguir ciegamente a los "filósofos reyes"), lo convertía en padre de los ideólogos totalitarios. También es un audaz ataque a Hegel y Marx, como continuadores de aquél. Popper nos advierte que ese libro monumental puede y hasta debe leerse como "una nota al pie" de un libro anterior: La pobreza del historicismo. En él, Popper justifica su desconfianza "lógica" en las filosofías que pretenden desentrañar un sentido para la historia y, en consecuencia, presumen de predecir su curso y poder cambiarlo. A su vez, este ensayo es hijo de una reflexión previa, su Lógica del descubrimiento científico. Allí Popper reconsidera el viejo "problema de Hume": ninguna ley natural es absoluta pues, aunque éstas se cumplan regularmente, no es imposible que un día aparezca una excepción. Popper deduce que esa incertidumbre epistemológica obliga al científico a plantearse teorías que se ofrezcan a ser demostradas como falsas (que sean "falseables") en lugar de empeñarse en ser verificadas. Esta humildad de la razón científica - que reconoce la esencial precariedad de sus verdades - es la base lógica del posterior pensamiento libertario de Popper. Si no podemos asegurar la verdad absoluta de una ley científica, mucho menos podemos aseverar la verdad de una "ley social". La ley pertenece al derecho; fuera de ese campo, especialmente en la historia, es una metáfora.

En su ensayo "Popper al día" (1992) Vargas Llosa asume aquellas ideas de su nuevo maestro: "[...] en la historia no existen 'leyes'. Ella es, para bien y para mal - Popper y muchos creemos lo primero'libre', hija de la libertad de los hombres, y, por lo tanto, incontrolable, capaz de las más extraordinarias ocurrencias" ${ }^{2}$.

A Vargas Llosa lo sorprende la coincidencia entre esa noción de la historia y sus convicciones como novelista. La historia real es un caos abigarrado que los historiadores ordenan artificialmente, al escribirlo, ansiosos de darle un sentido e incluso predecir su futuro, sin lograrlo. "La concepción de la historia escrita que tiene Popper se parece como dos gotas de agua a lo que siempre he creído es la novela: una organización arbitraria de la experiencia humana que defiende a los hombres

${ }^{2}$ Mario Vargas Llosa, "Popper al día”, Vuelta No 189 (marzo 1992), p. 28 . 
contra la angustia que les produce intuir el mundo, la vida, como un vasto desorden"3.

Los desengaños históricos y estas lecturas le descubrieron a Vargas Llosa la similitud entre su idea de la novela — un artefacto que presta sentido a lo inextricable - y esas nociones liberales - la historia real como misterio irredimible. Pero sus lectores atentos ya habían intuido, algo similar, antes: tal manera de entender la historia — personal y colectiva - emanaba, en forma natural y poderosa, de sus novelas iniciales. Demostración del poder autónomo de la ficción, que sorprende a su propio creador: los personajes expresaron antes que el autor lo que este pensaba.

Al adoptar el ideario liberal Vargas Llosa fue consecuente con su modo más antiguo e íntimo de ver y expresar el mundo. La intuición literaria del novelista y su poética realista, se adelantaron a su razón política. Sus novelas iniciales son más coherentes con el liberalismo descubierto después, que con el marxismo revolucionario o el compromiso sartreano que profesaba cuando las escribía. Esa es la consecuencia que cabe pedirle a un artista: que sus ideas sigan a su mirada. No a la inversa.

\section{Una libertad realista}

Contra la creencia vulgar en el idealismo de los artistas, los buenos narradores se especializan, por exigencia de su oficio, en conocer la realidad para poder reinventarla. El realismo narrativo de Vargas Llosa fue, desde un comienzo, no sólo un estilo, sino una manifestación de su sentido común. De su preciso entendimiento del realismo literario, "artefacto" para representar esa libertad limitada que llamamos experiencia, deriva su desconfianza hacia los artefactos intelectuales que pretenden reemplazar la realidad (la libertad), en lugar de expresarla. No sé si el novelista comprometido de esos años voceó alguna vez aquel lema del París de 68: "seamos realistas, pidamos lo imposible". Pero, en sus primeras novelas, los personajes de afán revolucionario, los utopistas que piden lo imposible, se desbarrancan al desastre personal y colectivo.

La ciudad y los perros (1964) termina con la derrota de los perros idealistas. Y la victoria de la ciudad realista. La ciudad "aterriza" al

\footnotetext{
${ }^{3}$ Ibídem.
} 
Poeta y al Jaguar, al romántico pusilánime y al machista valiente. Ni el machismo del Jaguar ni la sensibilidad del Poeta, como visiones idealizadas que son, pueden dar cuenta de la complejidad del mundo que les espera.

El Poeta delata al Jaguar porque cree que mató al Esclavo (y se atormenta pensando que él no lo defendió). Luego se desdice, amenazado por los oficiales con revelar su tráfico de novelitas porno. El Jaguar jura que él no lo mató y desfigura a golpes al Poeta. En el epílogo, conocemos que el Jaguar mintió: sí asesinó al Esclavo, porque éste delató a otro de los cadetes a cambio de ganarse un día de salida (salida de ese infierno donde el Jaguar y sus compinches lo humillaban) ${ }^{4}$. Cuando intenta confesarlo ya es tarde. El Poeta vuelve a su vida burguesa y reniega de su novia de clase baja, la que se buscó en los años del colegio para intentar asimilarse. Por su parte, el Jaguar busca a la misma chica y se casa con ella; la rapta, en un gesto romántico propio de su código, tan contrastado con la aburrida readaptación burguesa del Poeta. Sin embargo, también el Jaguar se ha aburguesado: el antiguo ladrón trabaja en un banco y vive con su suegra ${ }^{5}$. Lleva una vida honesta, tediosa, quizás feliz. Se sugiere — sólo se sugiere, porque la neutralidad del narrador flaubertiano es casi perfecta - que la honestidad intuitiva, salvaje, del Jaguar, ha sido "premiada" por la vida. Pero su encuentro final con el flaco Higueras, su amigo delincuente, no nos permite olvidar, y suponemos que a él tampoco, su pasado de ladrón, abusador y asesino. El Esclavo, que el Poeta no supo defender y que el Jaguar torturaba, está muerto. El Jaguar y el Poeta han pagado su madurez al precio de abandonar sus idealismos absolutos. Para ambos ser adultos significará aceptar una "libertad realista". Limitada por el mundo que les ha tocado y por el peso de sus primeros fracasos.

Ese tipo de desenlace, que conduce a los personajes supervivientes a asumir las responsabilidades de una libertad limitada, se repite en las dos novelas siguientes de Vargas Llosa. Tales epílogos han sido descritos como visiones sombrías, pesimistas, del mundo. Pero lo son sólo desde la perspectiva de un pensamiento utópico, que se empeñe en considerar como "fracaso absoluto" todo lo que no sea una victoria ideal. En verdad, si algo caracteriza a la gran tradición del realismo narrativo,

${ }^{4}$ Aunque Vargas Llosa, coherente con su realismo de la imprecisión, ha declarado "no estar tan seguro" de que el Jaguar matara al Esclavo.

${ }^{5}$ Para ser exactos: una tía de su mujer. 
especialmente en el género de la novela de formación, es la transacción con la realidad que sus personajes deben asumir al cabo de sus aventuras. El héroe regresa a casa armado de un conocimiento que le permite aceptar y a partir de allí controlar los límites de su libertad. El realismo narrativo de Vargas Llosa, me parece, es de esa especie.

\section{La historia como confusión}

La Casa Verde (1966) empata al final tres destinos principales. El arpista Anselmo, Fushía, Lituma, fracasan; en distintos grados, pero fracasan. Sólo algunas mujeres, Lalita, la Chunga, la Selvática, consiguen un éxito parcial, gracias al buen sentido o pragmatismo atribuido a esas mujeres, y opuesto a las ambiciones desmesuradas, irreales, de los hombres.

El terrible final de Fushía, en el leprosario del Amazonas donde sólo viene a visitarlo anualmente su compadre Aquilino, podría considerarse el destino más épico de la novela. Hay algo innegablemente simbólico en la huida del criminal, que burla a sus enemigos y a la ley para, aunque sea medio devorado por la lepra, seguir libre. Ese guiñapo humano, gimoteante, no se suicida ni se entrega. Su ambición y su violencia le han deparado un terrible destino. Pero es indesmentible, y así lo reconoce su único amigo, que Fushía ha escogido, paso a paso, esa vida. Ha preferido una libertad absoluta antes que la honestidad, la decencia o incluso el amor. ¿Cómo no ver en sus llagas el precio de esa libertad radical?

En el epílogo se prepara el velorio de Anselmo, emprendedor enérgico, luego arruinado arpista en el burdel refundado por su hija. El cura García y el doctor Zevallos, viejos testigos de esos dramas entrelazados, no logran ponerse de acuerdo sobre un sentido en la historia de Anselmo. ¿Absurdo, perversión, verdadero amor? La única conclusión es el misterio. Es mejor aceptar y respetar el misterio de la vida. El cura García parece asumirlo cuando accede a celebrar la misa de difuntos por el hombre al que tanto odió.

Si una sola de las líneas argumentales de esta intrincada novela no ofrece conclusiones evidentes, ¿qué esperar de la madeja enredada, anudada, que ellas forman? La historia humana -individual o colectiva- no tiene un destino claro. ¿O acaso su enredo, su confusión, es su claridad? Esta corazonada estaba en la poética de Vargas Llosa desde antes que la formulara en su política. 


\section{EI honor de dudar}

El inicio de Conversación en La Catedral (1969) puede enlazarse con el final de La ciudad y los perros. Zavalita es el mediocre periodista que el Poeta podría llegar a ser, diez o doce años después de su salida del colegio militar, si le ocurrieran las cosas que a Zavalita. La escena inicial ocurre en la perrera de Lima. El zambo Ambrosio mata a palos a los perros vagos capturados. Se remacha, simbólicamente, el amansamiento de "los perros" que el Colegio Leoncio Prado había iniciado. El entumecimiento de los ideales y las ambiciones de la juventud, apaleados por la ciudad.

Contra lo que suele decirse de ella, la famosa pregunta de $\mathrm{Za}-$ valita es, sobre todo, acerca de un fracaso personal antes que nacional: ¿cuándo me jodí yo? Las respuestas que se da, forzosamente imprecisas, hipotéticas, remiten a otras preguntas. Todas giran sobre una intuición: me jodí cuando dejé de ser "puro"; y dejé de ser puro cuando me di cuenta de que no podía creer. Zavalita quisiera tener fe en algo, a pie juntillas, así como creen casi todos, sin preguntarse, sin dudas. ¿Qué se lo impide? Su libertad de conciencia.

Zavalita padece la libertad de su conciencia. Pero no renuncia a ella. Conciencia crítica sobre sí mismo, en primer lugar. Y luego sobre el mundo que lo rodea (“¿cuándo se jodió el Perú?”). No puede creer en los valores burgueses de su familia tanto como no puede creer en la autenticidad de la vida popular ("En San Marcos, los cholos se parecían horriblemente a los niñitos bien, Ambrosio" ${ }^{\prime 6}$ ). Descree del comunismo de sus amigos de la universidad, del periodismo que será su profesión, del amor romántico, del honor; excepto del honor de dudar. Su falta de fe no proviene de un desengaño preciso (tendrá muchos), es un modo de ser: su intrínseca tendencia a buscar el lado falso de lo que parece verdadero. Su intuición de que las malas explicaciones son las que explican demasiado.

La interpretación usual dicta que Zavalita es un ejemplo de mala conciencia, en el sentido sartreano. Es un burgués culposo que no consigue dejar de serlo. Posiblemente el propio Vargas Llosa pensara así de su personaje mientras lo creaba. Pero Zavalita está más cerca de un libre

${ }^{6}$ Conversación en La Catedral, en Obras completas II, 2004, p. 120. Todas las citas de novelas siguen la edición de Obras completas, Galaxia Gutenberg, 2004. 
pensador que de un burgués culposo. Su actitud es más realista que neurótica. Zavalita ejerce su libertad de conciencia mediante ese realismo doloroso al que no está dispuesto a renunciar. Es más realista reconocer que no sabemos, antes que asegurarnos contra lo desconocido. Algo que, en política, Vargas Llosa sólo descubriría después. Resulta tentador pensar que el personaje se lo enseñó a su autor.

Conversación en La Catedral, al contrario que una novela de denuncia, no sólo pinta de gris a la dictadura de Odría, también los revolucionarios jovencitos y los rebeldes maduros salen manchados de hollín. Esa mediocridad de los protagonistas se reafirma por la equivalencia de sus voces en el coro de la novela. Una "coloratura" moral plomiza - como la garúa limeña - marcada por las sempiternas dudas de Zavalita. "Lo peor era tener dudas, Ambrosio, y lo maravilloso poder cerrar los ojos y decir Dios existe, o Dios no existe, y creerlo"7.

Pero Zavalita no puede cerrar los ojos. A sus ansias de seguridad intelectual y espiritual opone y prefiere la honestidad de sus dudas. Prefiere el gris porque las grandes oscuridades y luces que alternativamente lo enceguecen y deslumbran provocan más daño que esa posición intermedia. Si se niega a militar en la fracción comunista a la que se une todo su grupo e incluso la joven de la que está enamorado, es porque valora más su libertad de dudar que la seguridad de creer.

Implícita va la intuición de que la historia social no es predecible, por las mismas razones que su historia particular es sorprendente e ingobernable hasta para él mismo. "Lo que pasa es que ni eso [su matrimonio] lo decidí yo. Se me impuso solo, como el trabajo, como todas las cosas que me han pasado. No las he hecho por mí. Ellas me hicieron a mí, más bien" 8 .

La casualidad rige el mundo, por lo menos tanto como la voluntad. Ambas fuerzas forman un entramado infinitamente complejo, que nadie puede desentrañar completamente $\mathrm{y}$, por eso, sería pernicioso intentar controlar totalmente.

\section{Una poética de la libertad}

La ciudad y los perros, La Casa Verde, Conversación en La Catedral, esas tres primeras novelas podrán interpretarse de muchos modos, pero uno salta a la vista: no representan la ideología que su au-

\footnotetext{
${ }^{7}$ Ibídem, p. 129.

${ }^{8}$ Ibídem, p. 514.
} 
tor profesaba públicamente, en los años sesenta, cuando las escribió y publicó.

En esa década, Mario Vargas Llosa se definía como marxista y sartreano. Como marxista -ideológico, no militante - adhería a una interpretación total del mundo, capaz de anunciar e incluso cambiar el curso de la historia. Como sartreano creía que el escritor comprometido podía contribuir decisivamente a ese cambio.

Esas novelas discrepaban con su autor. Si bien nos alertan ante las injusticias representadas, evitan ofrecer interpretaciones unívocas acerca de sus causas, soluciones o salidas. La cruda descripción de las injusticias y alienaciones en la vida social y política del Perú y por extensión de Latinoamérica, podría ser tomada — superficialmente- por denuncia política. Pero la forma coral de estas ficciones contraviene ese tipo de compromiso, subordinándolo a una poética de la libertad individual.

La estructura narrativa usual en Vargas Llosa oscila entre un dueto de puntos de vista y un gran coro de narradores, alternados. Ya sea a dúo, o en coro, personalmente o representados por un narrador polifónico, los protagonistas ofrecen distintas versiones de sus experiencias y de la historia social que viven. El entrelazado de sus voces las armoniza estéticamente, mientras se contradicen y a menudo empatan éticamente. La neutralidad del autor las hace equivalentes; los juicios de valores quedan al arbitrio del lector.

Los comienzos in media res nos arrojan a la acción sin prepararnos. El argumento no avanza linealmente. Salta y zigzaguea de modos impredecibles, de pronto se estanca, y luego retrocede o gira en círculos, o brinca hacia el imprevisto futuro. Ese vértigo reproduce la sensación de caos, de imprecisión, del tiempo real.

Las explicaciones sobre los motivos de los personajes y las causas que los empujan siempre las obtenemos después, a la larga, demasiado tarde e incompletas. Tal como acostumbra dárnoslas la vida y la historia. (Un método que también coincide, "anticipadamente", con las ideas de Popper: "La esencia de un hombre — su personalidad - sólo puede ser conocida a medida que se desenvuelve en su biografía"9.)

Antes de que postulara una política de la libertad, Mario Vargas Llosa practicó una poética de la libertad. Esa estética, expresada desde

\footnotetext{
${ }^{9}$ Karl Popper, The Poverty of Historicism, 2002, p. 30 (T. del A.)
} 
muy temprano, es decididamente antiutópica (incluso cuando su autor profesaba un utopismo casi furioso). Los mecanismos de su poética - las mudas, los vasos comunicantes, las cajas chinas, los diálogos telescópicos - atestiguan ese universo caótico que, por serlo, resultaría inexacto y deshonesto representar mediante un discurso lineal y unificador. Estos mecanismos sugieren a un autor que no crea un mundo sino que, más bien, lo sondea. La naturaleza de esas herramientas indica su propósito: es demasiada ambición crear una realidad nueva; ya es mucho si logramos establecer nuevos contactos entre elementos de lo real. Contactos que ayudarán a que la realidad se exprese gradualmente por sí misma, sin imponerle un sentido. Dicha poética coincide, avant la lettre, con la idea del reformismo, o ingeniería social fragmentaria, de Popper. También en esto Vargas Llosa fue un liberal antes de reconocerse como tal.

La "novela total", que Vargas Llosa a veces ambiciona, se parece más a un gigantesco collage que a una imagen singular, única del cosmos. Si rivaliza con este no lo hace en unidad sino en dispersión, en incoherencia, en fluidez constante.

Un misterio gozoso de este método es el contraste entre la ingeniería de la obra y la improvisación que aparenta. "La casi matemática concepción arquitectónica de sus novelas [...] no es percibida como tal por el lector", ha notado Ricardo Cayuela ${ }^{10}$. Representación realista de un contraste sicológico. El orden es una aspiración perpetuamente insatisfecha de la mente, un vaso siempre desbordado por el desarreglo propio de la existencia. A mayor desarreglo, mayor libertad; y mayor nostalgia de una forma que pueda ordenarla, sin matarla.

La autonomía de la ficción — clave en esta poética- supone esa libertad nostálgica de los personajes. Y nos consiente una analogía simple: la ficción debe ser tan autónoma como el individuo en una sociedad libre. Las novelas deben dar independencia a sus personajes para contradecirse entre ellos y consigo mismos. Los derechos de los personajes priman sobre los del autor, que representa el poder y por lo tanto debe controlarse y ser controlado (por el lector). El novelista concebido como árbitro y no como un líder de su relato. El lector — semejante al ciudadano que, como sujeto tributario, debe ser el dueño del Estado y no a la inversa - es el verdadero propietario de la novela.

${ }^{10}$ Ricardo Cayuela, Mario Vargas Llosa, 2008, p. 25. 
La neutralidad del autor, casi "administrativa", llega a tanto que, si bien esas novelas de Vargas Llosa describen un mundo perverso, que debería cambiar, un lector atento también reconocerá que los personajes han elegido, en gran medida, la vida que llevan; o al menos su forma de llevar ese destino. Ni el Poeta, ni Zavalita, ni Lituma —ni los lectorestolerarían de buen grado que un autor todopoderoso cambiase la manera de equivocarse que han escogido. Su rebeldía ha sido, antes que nada, contra los poderes que creen saber mejor que ellos lo que les conviene. El derecho a encariñarse hasta con la miseria, y sobre todo con la mediocridad, libremente elegidas, es una de las intuiciones más poderosas que comunican estas novelas.

Esa repugnancia hacia el intervencionismo del autor, incluso cuando restan profundas contradicciones éticas, calzaba mal con el escritor revolucionario. Por mucho que se fuerce la interpretación de esas novelas su estética contradice un dirigismo o "centralismo" del escritor. En cambio, testimonian una constante y consecuente preferencia por la libertad individual de los seres imaginarios. Y, podemos presumir, también muestran una preferencia por la libertad de los seres reales (que somos imaginarios en la imaginación de los demás).

\section{Una objeción}

En su ensayo "Popper al día" Vargas Llosa afirma, repitámoslo, que la novela es: "una organización arbitraria de la experiencia humana que defiende a los hombres contra la angustia que les produce intuir el mundo, la vida, como un vasto desorden". Y más adelante agrega: "El miedo a reconocer su condición de seres libres no sólo ha fabricado tiranos [...]; también grandes novelas".

No está prohibido discrepar con Vargas Llosa. Creo que las buenas novelas no nos "defienden" del vasto desorden del mundo, ni son frutos del miedo. Por el contrario, nos enfrentan valerosamente a la arbitrariedad de lo real.

Desde luego que las hay de ese tipo: "novelas defensivas", que nos protegen de la realidad, o nos evaden de ella. Pero no son grandes novelas (excepto, quizás, en sus tiradas). Y, desde luego, las grandes novelas de Vargas Llosa no son de esa especie.

Además, esa idea de la novela como organización artificial, que nos defiende del caos real, contradice aquella otra que Vargas Llosa 
suele postular: la lectura de ficciones nos hace más libres. Una de dos: si la novela "nos defiende del vasto desorden del mundo", entonces sería como la "historia escrita" que rechaza Popper: un territorio artificialmente regulado donde reconquistamos la seguridad de un tiempo arcaico cuando no éramos individuos sino tribu (el tiempo de "El hablador"). Pero en este caso la novela no nos liberaría. Nos "aliviaría" de la libertad.

Si la novela ha de hacernos más libres lo hará representándonos el mundo anárquico e imprevisible, en el cual vivimos. Representación que gran parte de los demás relatos - religiosos, históricos, ideológicos, culturales - tienden a escamotear. Así la novela no nos "defenderá" sino que nos animará a enfrentar la arbitrariedad del universo cultural y material.

Sí, la lectura de ficciones libera. Pero esta convicción vargasllosiana concuerda mejor con la valentía que con el miedo. Puesto que la libertad siempre implica riesgo, sólo los relatos que nos arriesgan a enfrentar la incoherencia de lo real nos hacen más libres. En tanto que las malas ficciones - y los relatos "historicistas" - nos evitan tal molestia organizándonos un mundo que, en la realidad, siempre es un laberinto.

La posibilidad de "vivir" otras vidas, que Vargas Llosa añade como gran atractivo de la ficción, sólo es liberadora cuando esas vidas alternativas desprotegen nuestra conciencia, y así la amplían. Vivir imaginariamente otras vidas levanta el "velo de Maya" de las convenciones y rutinas que nos protege del azar y sus sinsentidos.

De más está decir que en las buenas novelas encontramos una sutil combinación entre arbitrariedad defensiva y representación valiente de lo arbitrario. El buen "hablador" es como el buen prestidigitador: con una mano nos indica mirar hacia otro sitio, mientras con la otra hace el truco delante de nuestros ojos. Con una mano traza un orden que nos distrae y reconforta, con la otra devela el misterio que nos hace temblar. La menor distancia entre sus manos da la medida del riesgo que corre, de su valentía y destreza. El mal mago se cubre con una nube de humo (o de tinta).

Lo que la narrativa de calidad representa mejor es la aventura de la libertad. No es otra manifestación del "historicismo" popperiano. No es un orden, sino la posibilidad, a la que rara vez nos entregamos, de vivir conscientemente el desorden de la existencia, como precio de ser libres. 


\section{Un humor rebelde}

Sus tres primeras novelas sugerían que el joven Vargas Llosa era un liberal sin saberlo, que practicaba una poética de la libertad antes de formular una política de la libertad. Sus dos novelas siguientes, publicadas durante los setenta, Pantaleón y las visitadoras (1973) y La tía Julia y el escribidor (1977), ampliarán la apuesta instintiva de Vargas Llosa por la libertad individual y social, contra las conciencias y las sociedades cerradas. Y lo harán mediante un recurso nuevo: un humor rebelde antitético de las seriedades marxista y sartreana que su autor todavía profesaba. Ambas obras delatan una irreprimible rebeldía creativa, que estalla en alegres carcajadas ante el rostro grave de esos pensamientos utópicos que quisieran limitarla y encauzarla.

Pantaleón... entraña un cómico pero efectivo elogio de la iniciativa individual contra la burocracia estatal. La tía Julia ... ridiculiza el estatuto mismo del escritor que se sueña demiurgo de su época y poder social.

El capitán Pantaleón Pantoja recibe órdenes de trasladarse a la Amazonía para crear un servicio de "visitadoras", prostitutas que deben atender a las distantes guarniciones de la selva. Los reclutas, destacados allí por largos períodos, acosan a las pocas lugareñas provocando conflictos peligrosos, incluso, para la seguridad nacional. Pantoja debe crear ese servicio auxiliar de las fuerzas armadas, en secreto, fuera de la estructura regular. Su propia familia debe ignorar lo que hace y hasta se le obliga a desprenderse de su venerado uniforme. El más brillante oficial de intendencia del ejército peruano se halla convertido, de pronto, en un empresario privado. O para ser más precisos, en algo así como el gerente de una empresa autónoma del Estado, de propiedad pública (pero secreta), con gestión privada.

A corto andar, Pantaleón transmuta ese experimento descabellado en una empresa modelo. Al tiempo que descubre en sí mismo capacidades de emprendedor que sólo aguardaban la relativa autonomía que tiene ahora para manifestarse. Su boyante empresa no sólo provee la oferta sexual que se le pedía, sino que crea una demanda nueva, ansiosa. Como en todo negocio floreciente su problema ya no será encontrar clientes o llegar a ellos; su desafío será cómo crecer al ritmo de la demanda incontenible que su éxito va generando. "Pechuga", "Peludita", "La Brasileña" y la otra decena de prostitutas iniciales no dan abasto. 
Todas las putas del Amazonas quieren enrolarse; todos los soldados y buena parte de los civiles quieren disfrutar del servicio. Las visitadoras aumentarán a veinte y luego a cuarenta y a cincuenta. Una de ellas, Maclovia, resume así el atractivo de la nueva empresa: "La tranquilidad de saber que el trabajo es legal, no vivir con el susto de la policía, de que los tiras te caigan encima y te saquen en un minuto lo que has ganado en un mes. [...] Hasta los cafiches andaban mansitos"11.

El éxito de Pantoja se basa no sólo en sus dotes de buen administrador (excepcionales, sus amigos lo apodan "el Einstein del cache"). La clave es una receta liberal, por antonomasia, para los mercados del crimen: legalizarlos. En este caso, legalizar la prostitución.

Organizando un cuerpo de prostitutas para el ejército, el capitán Pantaleón Pantoja hace aflorar una economía sumergida, plagada de violencias e injusticias, reemplazándola por otra donde se regula $-\mathrm{y}$ protege - la oferta y demanda de estos servicios. Pantaleón crea, incluso, un dinero especial, los vales con que los soldados pagan estos servicios se negocian, transformándose en un nuevo circulante. Legalizando el mercado informal de la prostitución, y convirtiéndolo en un negocio legítimo, Pantaleón cosecha el contento unánime de clientes y prostitutas. Y el odio jurado de los anteriores "empresarios" del ramo.

Los proxenetas y sus protectores (policías, inspectores y funcionarios municipales) que medraban gracias a la ilegalidad de la prostitución, explotando al eslabón más débil e indefenso en este comercio invisible, las putas, se revuelven contra una legalización que cancela sus privilegios y los vuelve irrelevantes como intermediarios.

Pero no sólo los proxenetas pierden su trabajo. También los dueños de la "economía moral", cuyo negocio depende de las prohibiciones al libre comercio sexual, perderían influencia si el ejemplo de Pantoja cunde. Todo un gremio de curas, periodistas tartufos, políticos cínicos, beatas religiosas y laicas, ven amenazados sus privilegios de voz y sus prestigios sociales, a consecuencias de esta revolución en el mercado del sexo amazónico.

Promediando la novela, Pantaleón se encuentra en previsibles y serios problemas. Sus patrocinadores en el ejército recapacitan. "Caracho. Esta cojudez se está poniendo tenebrosa", debe reconocer el general "Tigre" Collazos. La deseada satisfacción sexual de la tropa

${ }^{11}$ Pantaleón y las visitadoras, en Obras completas II, 2004, p. 792. 
amenaza con liberalizar las costumbres de toda la Amazonía, jacaso de todo el Perú!

No en balde, esa es la nueva ambición del enfebrecido capitán Pantoja. Tras su primer año la empresa de ese "Einstein del cache" presenta un balance espectacular: "un total de 62.160 prestaciones [...] guarismo que, aunque muy por debajo de la demanda, prueba que en todo momento el Servicio utilizó su potencia operativa al máximo de su rendimiento, 'ambición suprema de toda empresa productora"'12.

Tamaño éxito industrial se revela como una tentación infecciosa y un desafío nacional. ¿Cómo liberalizar el sexo en un sector del país sin liberar de rebote, por reacción en cadena, toda la sociedad y su economía?

El absurdo cómico que dramatiza la novela emanaba de la génesis contradictoria del experimento. Es el ejército, una institución estatal, jerárquica, enemiga por definición de la libre iniciativa, el que irreflexivamente se embarcó en una empresa liberalizadora en lo económico y moral. La rígida burocracia militar es el contraste perfecto para la explosión de libertades individuales que trae consigo el ensayo de legalizar el comercio sexual.

Políticamente incorrecta, Pantaleón y las visitadoras confirma que la liberalización económica fomenta la liberalización de las costumbres. Al legalizar a sus prostitutas y darles una dignidad laboral, salarios justos y seguridad que no conocían, el capitán Pantoja las libera, en no poca medida, de sus servidumbres. Son putas pero dueñas de su negocio, dueñas de sí mismas, es la excitante conclusión a la que llegan varias de ellas. Y esto es imperdonable para el machismo que no sólo las usaba sino que las poseía.

En Pantaleón el machismo representa, para el sexo, lo que el Estado para la política y economía: el impulso de intervenir, coartar y controlar, por la fuerza, la libertad del deseo. Si el machismo es una conducta infecciosa, agravada por la patota, el nacionalismo es la forma masiva y política del machismo. La liberación de las putas deviene un problema nacional.

El ejército entiende al fin su gran error. Liberar a las trabajadoras del sexo reta al machismo, que las fuerzas armadas representan en su forma ampliada: la nación. Pantoja es castigado sacándolo de las calenturas de la selva para enviarlo a las frías alturas de la puna.

${ }^{12}$ Ibídem, p. 756. 
Pantaleón y las visitadoras, bajo las formas de una novela cómica, ensalza la iniciativa individual y la creatividad empresarial, como agentes de cambio en una sociedad cerrada, jerárquica, estancada por el miedo a la libertad.

\section{Preciosos ridículos}

Si Pantaleón conllevaba un alegre elogio de los poderes de la iniciativa empresarial, imposible de conciliar con el marxismo — ni aun heterodoxo-, La tía Julia y el escribidor pondrá en solfa el programa del escritor sartreano, su engreimiento e importancia social. E incluso el paradigma de la literatura como utopía, es decir, como verdad alternativa.

La tía Julia entrelaza capítulos autobiográficos con episodios de radioteatros escritos por uno de los personajes en esa autobiografía, el escribidor boliviano de culebrones, Pedro Camacho. La memoria novelada que hace Vargas Llosa de sus primeras armas como escritor, en la Lima de los años cincuenta, y su romance con una mujer diez años mayor, que además es su tía política, rivaliza en melodrama con las radionovelas de Camacho. En ciertos aspectos, la vida real supera los absurdos del radioteatro. Barajar así los melodramas reales con los ficticios facilita la risa y la catarsis consiguiente. El padre de Vargas Llosa lo amenaza con castigar el escándalo familiar y su desobediencia: "te mataré de cinco balazos como a un perro, en plena calle"13. Ese recuerdo de un trauma real leído codo a codo con uno de los desopilantes libretos de Pedro Camacho, aplaca la memoria dolida revelándola como una versión del pasado, cuyo sentido cambia según el contexto en que la pongamos.

La tía Julia involucra una crítica a las versiones "definitivas" de la realidad. El relato literario supuestamente más veraz, el autobiográfico, se entrevera con el más mentiroso, el melodrama. Desde la primera mezcla (la historia del Dr. Quinteros y sus sobrinos incestuosos), somos inducidos a pensar que ambos relatos son veraces o igualmente falsos (el incesto también es el "pecado" de la tía Julia). El efecto es equiparar la memoria y la ficción como formas de la literatura. Todo lo real, cuando se relata, es ficción.

${ }^{13}$ La tía Julia y el escribidor, en Obras completas II, 2004, p. 1216. 
Equiparar memoria y melodrama tiene un efecto similar sobre el culto de la literatura exaltada a sacerdocio. Los serios y denodados esfuerzos para convertirse en escritor que hace un jovencísimo Vargas Llosa - de dieciocho años, en esa época—, conviven con los no menos serios y denodados trabajos del escribidor profesional, Pedro Camacho. De hecho, algunas de las historias que el aspirante borronea y luego rompe son más improbables, ridículas y cursis que los rocambolescos libretos del radioteatrista. No se trata de que la inexperiencia juvenil del novato y la inepcia del escribidor barato igualen sus productos. Los asemeja algo más sustancial: la gravedad con la que ambos cultivan sus vocaciones. Porque Camacho no es ningún mercenario. Cree a pie juntillas en la trascendencia profunda de su oficio. Sus historias son arte y el arte enaltece al que lo crea y al que lo recibe. Por eso, piensa Camacho, el artista escritor debe dedicarse en cuerpo y alma, como él, a su oficio. Vivir para el arte, de modo que la vida se transforme en arte.

Varguitas, el casi adolescente candidato a escritor, siente de modo parecido. Aunque no aprueba la narrativa improbable y cursi de Camacho, admira su dedicación ascética y su torrencial voluntad de escribir. Varguitas reprueba la estética de Camacho pero admira su ética. Lo siente como un hermano escritor que busca, por caminos distintos, el mismo grial sagrado de la literatura. "No quería de ningún modo ser un escritor a medias y a poquitos, sino uno de verdad, como ¿quién? Lo más cercano a ese escritor a tiempo completo, obsesionado y apasionado con su vocación, que conocía, era el radionovelista boliviano: por eso me fascinaba tanto" 14 .

La tía Julia ... pone en solfa la seriedad de la literatura, cuando ésta se toma a sí misma demasiado en serio. Y, por ende, parodia las ilusiones del escritor acerca del poder que la ficción pueda tener sobre la sociedad. Camacho y Varguitas son extremadamente serios acerca de la literatura. Camacho por loco y Varguitas por joven. Vargas Llosa recuerda, con temprana pero implacable madurez, el fanatismo del novato que no sólo defendía sus dogmas literarios, sino que buscaba imponérselos a los demás, censurando y prohibiendo. He aquí a Marito enseñándole a la tía Julia lo que NO DEBE LEER: "Había establecido una censura inquisitorial en sus lecturas, prohibiéndole todos sus autores favoritos, que empezaban por Frank Yerby y terminaban con Corín Tellado"15.

\footnotetext{
${ }^{14}$ Ibídem, p. 1073.

${ }^{15}$ Ibídem, p. 1104.
} 
Esa mofa de las pretensiones exageradas de la alta y la baja literatura sugieren que, hacia fines de los setenta, Vargas Llosa ya no cree que la ficción sea tan trascendente o sagrada como creían el joven Varguitas y el escribidor Camacho. La literaria es una mirada poderosa sobre el mundo, pero no superior a otras perspectivas o razones. Puede ser complementaria y acaso iluminadora. Pero sobrevalorarla convierte al escritor en un precioso ridículo.

La tía Julia... insinúa una revisión de los modelos literarios más caros a Vargas Llosa, hasta entonces: Sartre como crítico y Flaubert como narrador.

Pedro Camacho puede ser leído como una caricatura de Flaubert. Ambos comparten la dedicación religiosa al arte y la grandilocuencia acerca de sus posibilidades de redención, sumadas a un característico desprecio — casi patológico- por la especie humana real. Camacho, que, podemos tener la seguridad, jamás ha leído a Flaubert, comparte con este algunas de sus manías, como la de disfrazarse de sus personajes o rodearse de objetos alusivos a sus ficciones. "¿Qué cosa es el realismo, señores, el tan mentado realismo qué cosa es? ¿Qué mejor manera de hacer arte realista que identificándose materialmente con la realidad?" (Siguiendo con la broma, dejemos para el lector decidir la atribución de esta cita: ¿de Flaubert o de Camacho?.)

En cuanto a Sartre, a mediados de los setenta el "sartrecillo valiente", como lo llamaban a Vargas Llosa, va en tren de un revisionismo alarmante. El escritor comprometido sartreano, con sus aires de mandarín y sus ambiciones de conciencia social, es un avatar probable del escritor pretencioso, en su versión joven o madura, de alta o baja literatura, ridiculizado en La tía Julia... Vargas Llosa conjura ese avatar mediante la risa. El dogma sartreano del escritor comprometido resulta invalidado por esta crítica jocunda de la literatura "demasiado seria". El creador ha intuido, antes que el intelectual, la incompatibilidad del compromiso sartreano con la poética de la libertad y el ideario liberal, que pronto va a suscribir explícitamente.

\section{Una ficción "falseable"}

José Miguel Oviedo afirma que tanto Pantaleón... como La tía Julia... representan "una visión paródica de la actividad escritural". Y así ponen en evidencia "algo crucial para un narrador realista: la dificul- 
tad (o imposibilidad) de escribir novelas que no alteren la misma realidad a la que quieren ser fieles"16.

Esa "dificultad" es más profunda incluso que una "imposibilidad". No se trata sólo de que Vargas Llosa hubiera descubierto, para mediados de los setenta, las dificultades de representación consustanciales a la narración realista. Supongo que las conocía desde sus comienzos. Se trata de que, en ese proceso, su intuición de novelista había llegado ya a las conclusiones que su razón de intelectual descubriría más tarde: no es posible, ni siquiera deseable, una representación exacta o definitiva de la realidad, porque ella contradeciría la naturaleza irreductible y parcial de la misma. De manera similar a su trilogía inicial, estos dos libros de Vargas Llosa delataban una sensibilidad liberal, latente.

Veinte años más tarde, Vargas Llosa lo reconoce de forma inequívoca, al decir de Pantaleón...: "Por increíble que parezca, pervertido como yo estaba por la teoría del compromiso en su versión sartreana, intenté al principio contar esta historia en serio. Descubrí que era imposible, que ella exigía la burla y la carcajada. Fue una experiencia liberadora..." $" 17$.

Esa carcajada es su nueva hipótesis. Las hipótesis de la ficción deben ser como las hipótesis de la ciencia, para Popper, deliberadamente destinadas a ser falseadas en lugar de verificadas. Esa carcajada subraya la esencial falseabilidad de la literatura y la emparienta con la mejor actitud científica.

Privilegio de la ficción, esta va incluso más lejos que la ciencia: no sólo se ofrece para ser falseada, sino que se declara imposible de comprobar. Paradójicamente, allí yace su poder.

El mayor poder de la literatura, en el mundo, le viene de declarar sinceramente su falsedad. Esa honestidad la distingue de relatos alternativos — historia, política, economía - que pretenden ser verdades definitivas, respuestas totales y abarcadoras.

La narrativa no es verdad. Ni siquiera es una verdad entre otras. No se trata de una veracidad alternativa. Se trata de una mentira poderosa. Entre cuyos efectos, aparte de aquellos como distracción y juego, tan importantes, está el de hacernos notar que las demás verdades,

16 José Miguel Oviedo, Prólogo general, en Mario Vargas Llosa, Obras completas II, 2004, p. 20.

${ }^{17}$ Mario Vargas Llosa, Prólogo a Pantaleón y las visitadoras, en Obras completas II, 2004, p. 20. 
incluidas las científicas, o son provisionales o son también ficciones, relatos, mentiras.

Toda verdad que se pretenda absoluta y eterna es ficción. Pertenece al dominio de la literatura más que al de la ciencia. A esa gran literatura, "que no se atreve a decir su nombre", incumben también las verdades religiosas, cuando intentan cancelar el misterio del mundo.

La ficción resalta la inseguridad — vital e intelectual - propia de la experiencia humana. Es cierto que, al hacerlo, acrecienta nuestra inconformidad, como asevera a menudo Vargas Llosa. Pero allí empieza, y también termina, el enorme poder liberador de la literatura. No necesita prologarse en supuestas capacidades de cambiar la realidad o mejorarla. No nos propone que reemplacemos este mundo inseguro por una versión mejorada, que algunos escritores iluminados conocerían.

La buena literatura hace algo mejor: refuerza nuestra desconfianza por las explicaciones completas, que olvidan la esencial provisionalidad de nuestras certezas. Y por tanto nos vacuna contra las verdades demasiado seguras de sí mismas. La ficción libera, sí, pero lo hace animándonos a descreer de los dogmas más establecidos. Enseñándonos que no hay verdad tan sagrada que no pueda ser reinventada.

Las cinco primeras novelas de Vargas Llosa muestran una sensibilidad liberal más poderosa que las ideologías que por entonces sustentaba.

La ciudad y los perros, La Casa Verde y Conversación en La Catedral, expresan una clara poética de la libertad, que contradice los determinismos históricos.

Las dos siguientes, Pantaleón y las visitadoras y La tía Julia y el escribidor, ponen en duda los modelos y dogmas de su formación: sus creencias marxistas y sartreanas, en busca de una plena autonomía intelectual. Al hacerlo, Vargas Llosa jaquea también su propia autoridad, la auctoritas del escritor, en pos de un pensamiento para el que no hay verdades intocables, ni siquiera las propias.

El dogmático Varguitas ya estaba maduro para reconocerse en el liberal Vargas Llosa. 


\section{REFERENCIAS}

Cayuela, Ricardo. Mario Vargas Llosa. México: Nostra Ediciones, 2008.

Popper, Karl. The Poverty of Historicism. London: Routledge, 2002.

Vargas Llosa, Mario. "Popper al día". Vuelta, No 184 (marzo 1992), México.

Obras completas II. Barcelona: Galaxia Gutteberg, 2004. 